\title{
Thai Parents' Perspectives towards Childcare Centres in Bangkok
}

\author{
Wipanee Pengnate \\ English Department, College of General Education and Languages, \\ Thai-Nichi Institute of Technology \\ Bangkok, Thailand \\ Email:wipanee@tni.ac.th
}

\begin{abstract}
The purposes of this study were 1) to investigate Thai parents' perspective towards childcare centres in Bangkok, and 2) to study additional suggestions from respondents. The research samples were 228 Thai parents using childcare centres in Bangkok in 2021 derived through Simple Random Sampling technique. The instruments for collecting the data were the rating-scale and open-ended questionnaire. Frequency, percentage, mean, standard deviation and content analysis were used for data analysis. The findings were as follows: 1) Thai parents' perspectives towards childcare centres in Bangkok were at a high level; and 2) other services and qualities were highly concerned. The Rise of Childcare centre trend in Thailand, opportunities and Recommendations in the childcare market were further demonstrated and discussed.
\end{abstract}

Keywords: Early Childhood Education, Childcare Centre Thailand, Childcare Quality and Service

\section{Introduction}

At present, the significance of childcare is obviously playing an essential role as the majority of parents now work, regardless the age of their children. Most families work out of necessity because the economic climate dictates that there must be two bread winners in order to the pay the bills. In this case, it might be demonstrated that parents may face the danger of losing a job or missing a promotion because of illness, pregnancy, or taking care of loved ones. This is because so many companies focus solely on the bottom line, it leaves too many parents having to look toward day care for a solution to their problem. According to Wieske (2015), his study presents that the bubble burst in the economy in 2008 causes a significant effect for the domestic income. Only married couples that have seen any economic growth in their household are those families where both parents are working. Consider that approximately seventy percent of mothers are currently in the labor force, including almost sixty-one percent of mothers with a child under the age of six years old. This is not just a women's issue anymore since the 
changing nature of our financial environment necessitates a two income household (Wieske, 2015).

The term of childcare, then, broadly defines as all types of education and care provided for young children. It is also used more specifically for the supplemental care of children from birth to age eight years by persons other than parents. Childcare is used for a variety of reasons, and programs vary by the number and age of children, the reason care is used, the preparation and status of caregivers, and the location of the care. Terminology varies in different countries although there may be similar concerns of low pay and status, and insufficient training for teachers (Katz 1999; Woodill et al, 1992). This is supported by Glynn et al (2013) who advocate that it is vital to provide universal, high-quality pre-K education to children- so called Early childhood education. The benefits of Early childhood education are addressed as better, more equitable long-term outcomes for children of divergent economic backgrounds. Therefore, investments in these programs help cultivate a future workforce, secure long-term economic competitiveness, and develop the nation's future leaders.

It is concluded by The Business Research company (2019) who states that the global market for child care reached a value of nearly $\$ 339.1$ billion in 2018 , having grown at a compound annual growth rate (CAGR) of $8.3 \%$ since 2014, and is expected to grow at a CAGR of $11.3 \%$ to nearly $\$ 520.4$ billion by 2022 .

\section{Demand for Early Childhood care in Thailand}

Child care has received increasing attention by Thai researchers in recent years, with particular attention to the impact of child rearing on child health and development and to the situation for women working in the formal sector (). An increase in the numbers of families where both parents are employed and a steady change in gender roles occurred in the historic period shown as Figure 1 (MICS, 2019). 
Figure 1: Attendance at Early Childhood Education Programmes

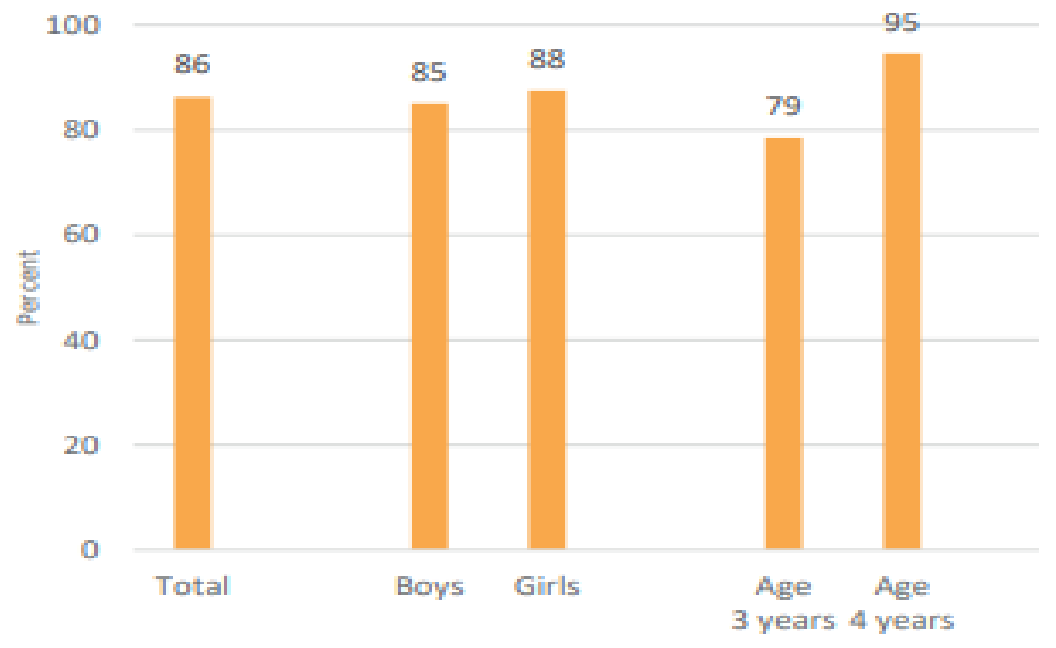

Figure 1 presented percentage of children age 3-4 years attending an early childhood education to engage in activities that promote learning and school readiness.

However, it is evident highlighted in Figure 2 that there is inadequate supervision of children in Bangkok (MICS, 2019).

Figure 2: Inadequate supervision of children

\begin{tabular}{l|c}
\multicolumn{1}{c|}{ Region } & $\begin{array}{c}\text { Left in inadequate } \\
\text { supervision }\end{array}$ \\
\hline National & $\mathbf{5}$ \\
\hline Bangkok & 3 \\
\hline Central & 5 \\
\hline North & 4 \\
\hline Northeast & 4 \\
\hline South & 6 \\
\hline
\end{tabular}


Figure 2 illustrates percentage of children under age five left alone or under the supervision.

The rise in childhood care trend is, then, furthermore, addressed by researchers at the Institute for Population Studies, Chulalongkorn University, who run a major study of the child care situation in Bangkok and Chiang Mai (Wongboonsin et al. 1991; Wongboonsin and Ruffolo 1992). While they find out a considerable increase in the percentage of children in non-maternal care in Bangkok in recent years, this change could be completely explained by the rise in women's educational levels and decline in fertility. Thus child's birth cohort is not found to be significant in determining type of care when included in a multivariate model including mother's education and occupation. In Chiang Mai the results are similar though a much higher percentage of children are found to be in formal care in urban Chiang Mai than in Bangkok. They do not find a strong relationship between type of care and child illness in either setting. This is relevant to the study of UNICEF Thailand (2019) who highlights that, in the last 20 years, Thailand has made impressive gains in Early Childhood Development (ECD). Approximately $85 \%$ of children aged 3-5 years now attend ECD centers or pre-primary education. Thailand has also rightly recognized that effective services for young children will only happen through cohesive and multi-sectoral policy investments to ensure the holistic development of all young children in Thailand. A more radical approach is supported by The Business Research company (2019) who indicates that AsiaPacific, including Thailand, is the largest market for child care, accounting for almost $38.4 \%$ of the global market. It is followed by Western Europe, North America and then the other regions.

\section{Purposes}

The purposes of this study were:

1) to investigate Thai parents' perspective towards childcare centres in Bangkok; and

2) to study additional suggestions from respondents.

\section{Research Methodology}

This study focused on Thai parents' perspective towards childcare centres in Bangkok which consists of population and samples as follows:

The population of this study was 1500 Thai parents using childcare centres in Bangkok in 2021.

The samples of this study were 228 Thai parents using childcare centres in Bangkok in 2021derived through Simple Random Sampling technique. 
Instrumentation

The instruments used for gathering the data were the rating-scale and openended questionnaire based on Thai parents' perspectives towards childcare centres in Bangkok.

The first part (Part 1) of the questionnaire asked for the demographic information of the respondents: Gender, Age, Household monthly income and Work sector. The second part (Part 2) concerned with Thai parents' perspective towards childcare centres in Bangkok. This part consisted of 10 items of Child Development, 5 items of Facilities and Equipment, and 5 items of Caregivers. The third part (Part 3) asked for opinions and suggestions of the respondents.

The five levels of Thai parents' perspectives used in the questionnaire were ranked as "The highest level", "High level", "Moderate level", "Low level", and "The lowest level". Responses from the questionnaires were subsequently coded. The data of the respondents' coded responses were statistically calculated and analyzed.

\section{Data Analysis}

Data analysis from questionnaire both single item and whole questionnaire which presented by a form of rating scale. These rating scales were calculated to find out mean and standard deviation and then translated based on criteria developed by Best (1981) as follows:

5 refers to The highest level

4 refers to High level

3 refers to Moderate level

2 refers to Low level

1 refers to The lowest level

This, then, is calculated into mean scores as a following formulation.

$1.00 \leq \overline{\mathrm{X}}<1.50$ refers to the lowest level.

$1.51 \leq \overline{\mathrm{X}}<2.50$ refers to low level.

$2.51 \leq \overline{\mathrm{X}}<3.50$ refers to moderate level.

$3.51 \leq \overline{\mathrm{X}}<4.50$ refers to high level.

$4.51 \leq \overline{\mathrm{X}}<5.00$ refers to the highest level. 
The collected data was analyzed using a computer program. The statistics used for analyzing the data were frequency, percentage, mean, standard deviation, and content analysis.

\section{Results}

Part 1: Results of the demographic data of the respondents

Table 1: Results of the Demographic Data of the Respondents 


\begin{tabular}{|c|c|c|}
\hline Demographic data of the respondents & $n$ & Percentage \\
\hline \multicolumn{3}{|l|}{ 1. Gender } \\
\hline 1.1) Male & 80 & 35.09 \\
\hline 1.2) Female & 148 & 64.91 \\
\hline Total & 228 & 100 \\
\hline \multicolumn{3}{|l|}{ 2. Age } \\
\hline 2.1) Less than 20 years old & 8 & 3.51 \\
\hline 2.2) 20-29 years old & 62 & 27.19 \\
\hline 2.3) 30-39 years old & 80 & 35.08 \\
\hline 2.4) 40-49 years old & 75 & 32.90 \\
\hline 2.5) 50-59 years old & 2 & 0.89 \\
\hline 2.6) 60 years old and above & 1 & 0.43 \\
\hline $\begin{array}{l}\text { Total } \\
\end{array}$ & 228 & 100 \\
\hline \multicolumn{3}{|l|}{ 3. Household monthly income } \\
\hline 3.1) Less than 20,000 Baht & 41 & 17.99 \\
\hline 3.2) 20,001-30,000 Baht & 83 & 36.40 \\
\hline 3.3) 30,001-40,000 Baht & 72 & 31.57 \\
\hline 3.4) 40,001-50,000 Baht & 22 & 9.65 \\
\hline 3.5) Above 50,001 Baht & 10 & 4.39 \\
\hline Total & 228 & 100 \\
\hline \multicolumn{3}{|l|}{ 4. Work sector } \\
\hline 4.1) Private sector & 54 & 23.68 \\
\hline 4.2) Government sector & 39 & 17.11 \\
\hline 4.3) Semi-government sector & 42 & 18.42 \\
\hline 4.4) Own business & 92 & 40.35 \\
\hline 4.5) Student & 1 & 0.44 \\
\hline 4.6) Not working & 0 & 0 \\
\hline 4.7) Others & 0 & 0 \\
\hline Total & 228 & 100 \\
\hline
\end{tabular}

Table 1 showed that percentages of respondents in genders ranged from $35.09 \%$ as male parents and $64.91 \%$ as female parents. For age, the percentages ranged from $3.51 \%$ for less than 20 years old, followed by $27.19 \%$ for $20-29$ years old, $35.08 \%$ for $30-39$ years old, $32.90 \%$ for $40-39$ years old, $0.89 \%$ for $50-59$ years old, and $0.89 \%$ for 60 years old and above. For household monthly income, 
the percentages ranged from $17.99 \%$ for less than 20,000 Baht, followed by $36.40 \%$ for $20,001-30,000$ Baht, $31.57 \%$ for 30,001-40,000 Baht, $9.65 \%$ for 40,001-50,000 Baht, and 4.39\% for Above 50,001 Baht. The last demographic variable was Work sector. The percentages ranged from $23.68 \%$ for Private sector, followed by $17.11 \%$ for Government sector, $18.42 \%$ for Semi-government sector, $40.35 \%$ for Own business, and $0.44 \%$ for student.

Table 2: Mean $(\overline{\mathrm{X}})$ and Standard Deviation (S.D.) of the Thai parents' perspectives towards childcare centres in Bangkok in Overall

\begin{tabular}{|c|l|c|c|c|}
\hline No. & \multicolumn{1}{|c|}{ Aspects } & $\overline{\mathrm{X}}$ & S.D. & Level \\
\hline 1. & Child development & 4.52 & 0.66 & Highest \\
\hline 2. & Facilities and Equipment & 4.60 & 0.64 & Highest \\
\hline 3. & Caregivers. & 4.75 & 0.63 & Highest \\
\hline \multicolumn{2}{|c|}{ Total } & $\mathbf{4 . 6 2}$ & $\mathbf{0 . 6 4}$ & Highest \\
\hline
\end{tabular}

The above table indicated that Thai parents had the highest level of perspectives towards childcare centres in Bangkok in overall $(\overline{\mathrm{X}}=4.62)$. The highest rank at the highest level was Caregivers ( $\overline{\mathrm{X}}=4.75$ ), followed by Facility and Equipment and Child development ( $\overline{\mathrm{X}}=4.60$ and $\overline{\mathrm{X}}=4.52$ respectively).

Table 3: Mean $(\overline{\mathrm{X}})$ and Standard Deviation (S.D.) of the Thai parents' perspectives towards childcare centres in Bangkok.in Child development

\begin{tabular}{|c|c|c|c|c|}
\hline No. & Components & $\overline{\mathrm{X}}$ & S.D. & Level \\
\hline 1. & Basic learning skill development & 4.87 & 0.87 & Highest \\
\hline 2. & Social skill development & 4.52 & 0.69 & Highest \\
\hline 3. & Self-help skill development & 4.41 & 0.79 & High \\
\hline 4. & Values learned & 4.30 & 0.47 & High \\
\hline 5. & Cooperative development & 4.45 & 0.59 & High \\
\hline 6. & Happiness children experience & 4.57 & 0.58 & Highest \\
\hline 7. & Child's progress assessment & 4.64 & 0.49 & Highest \\
\hline 8. & Frequency of progress assessment & 4.32 & 0.53 & High \\
\hline 9. & Parent-caregiver communication & 4.78 & 0.84 & Highest \\
\hline 10. & Learning environment & 4.29 & 0.79 & High \\
\hline & Total & 4.52 & 0.66 & Highest \\
\hline
\end{tabular}


The table presented that Thai parents had the highest level of perspectives towards childcare centres in Bangkok in Child development $(\overline{\mathrm{X}}=4.52)$. The highest rank at the highest level was "Basic learning skill development" $(\overline{\mathrm{X}}=4.87)$, followed by "Parent-caregiver communication" ( $\overline{\mathrm{X}}=4.60)$ whereas the lowest rank at a high level was "Learning environment" ( $\overline{\mathrm{X}}=4.29)$.

Table 4: Mean $(\overline{\mathrm{X}})$ and Standard Deviation (S.D.) of the Thai parents' perspectives towards childcare centres in Bangkok.in Facilities and Equipment

\begin{tabular}{|c|c|c|c|c|}
\hline No. & Components & $\overline{\mathrm{X}}$ & S.D. & Level \\
\hline 1. & Decoration of facility & 4.54 & 0.62 & Highest \\
\hline 2. & Toy quality & 4.62 & 0.67 & Highest \\
\hline 3. & Cleanliness of facility & 4.89 & 0.78 & Highest \\
\hline 4. & Layout of facility & 4.60 & 0.58 & Highest \\
\hline 5. & Furniture in facility & 4.35 & 0.55 & High \\
\hline & $\begin{array}{r}\text { Total } \\
\end{array}$ & 4.60 & 0.64 & Highest \\
\hline
\end{tabular}

The table demonstrated that Thai parents had the highest level of perspectives towards childcare centres in Bangkok in Facilities and Equipment ( $\overline{\mathrm{X}}$ = 4.60). The highest rank at the highest level was "Cleanliness of facility" ( $\overline{\mathrm{X}}=$ 4.89), followed by "Toy quality" ( $\overline{\mathrm{X}}=4.62)$ whereas the lowest rank at a high level was "Furniture in facility" ( $\overline{\mathrm{X}}=4.35)$.

Table 5: Mean $(\overline{\mathrm{X}})$ and Standard Deviation (S.D.) of the Thai parents' perspectives towards childcare centres in Bangkok.in Caregivers

\begin{tabular}{|c|l|c|c|c|}
\hline No. & \multicolumn{1}{|c|}{ Components } & $\overline{\mathrm{X}}$ & S.D. & Level \\
\hline 1. & Qualifications & 4.88 & 0.74 & Highest \\
\hline 2. & Supervision & 4.63 & 0.58 & Highest \\
\hline 3. & Attentiveness to child & 4.70 & 0.67 & Highest \\
\hline 4. & Handling of accidents & 4.87 & 0.59 & Highest \\
\hline 5. & Treatment to child & 4.65 & 0.57 & Highest \\
\hline & \multicolumn{1}{|c|}{ Total } & $\mathbf{4 . 7 5}$ & $\mathbf{0 . 6 3}$ & Highest \\
\hline
\end{tabular}

The table illustrated that Thai parents had the highest level of perspectives towards childcare centres in Bangkok in Caregivers ( $\overline{\mathrm{X}}=4.75)$. The highest rank at the highest level was "Qualifications" ( $\overline{\mathrm{X}}=4.88$ ), followed by "Handling of 
accidents" ( $\overline{\mathrm{X}}=4.87)$ whereas the lowest rank at the highest level was "Supervision" ( $\overline{\mathrm{X}}=4.63)$.

\section{Part 3: Opinions and Suggestions from the Respondents}

The opinions and suggestions from the respondents were listed as follows:

1. The qualifications of caregivers were highly concerned.

2. The childcare centre should be openness to feedback.

3. Communication should be given to parents frequently.

4. Schedule flexibility should be applied.

5. There should be high concern on sick policy to child.

\section{Conclusion and Discussion}

According to the study, it was found that Thai parents had the highest level of perspectives towards childcare centres in Bangkok. The highest level of perspectives was remarkably concerned on Caregivers. Thus, this study is vastly supported by the notion of Unicef Thailand (2019) who notes that the economic burden will be heavy on the relatively small demographic of today's children, to produce enough wealth to both maintain Thailand's current middle-income status. The only way to succeed against a challenge of such magnitude is to make sure that today's babies and young children will become an economic "powerhouse", delivering economic growth at similar levels to the past twenty years for the country.

Furthermore, the significance of caregivers' qualification is highlighted by Melhuish et al. (2013) who mention the essential of Early childhood education as that the positive long-term impacts that high-quality preschool and child care have on children and the economy.

Opportunities and Recommendations in the childcare market

Opportunities - The top opportunities in the global child care market will arise in the baby and child care segment, which will gain $\$ 124.9$ billion of global annual sales by 2022. The child care market size will gain the most in China at $\$ 52.1$ billion. Market-trend-based strategies for the child care market include leveraging technology to optimize services and enhance customer satisfactory levels, partnering with corporates to increase revenues and market shares, using AI technology for better childcare management, and adopting interest-driven learning methods to make learning more enjoyable for children. Player-adopted strategies in the child care industry include expanding operations through acquisitions, increasing public commitment to high quality learning, and building capable work force. 
Recommendations - To take advantage of these opportunities, The Business Research Company recommends the child care companies to focus on use of technological advances, expand in emerging markets, focus on expanding through collaborations, price competitively, leverage social media to maximize reach and focus on the middle-class population in emerging countries (The Business Research company, 2019).

\section{References}

Best, J. (1981). Research in education (4th ed.). New Jersey: Prentice Hall. Glynn, S.J., Farrell, J. and Wu, N. (2013). "The Importance of Preschool and Child Care for Working Mothers". Center for American Progress. Available https://www.americanprogress.org/issues/education-k12/reports/2013/05/08/62519/the-importance-of-preschool-and-child-carefor-working-mothers/.

Katz, L. (1999). "International Perspectives on Early Childhood Education: Lessons from My Travels". Early Childhood Research and Practice, 1(1). Available from http://www.ecrp.uiuc.edu.

Melhuish, E., Quinn, L., Sylva, K., Sammons, P., Siraj-Blatchford, I. \& Taggart, B. (2013). "Preschool af-fects longer term literacy and numeracy: results from a general population longitudinal study in North-ern Ireland, School Effectiveness and School Improvemen". An International Journal of Research, Policy and Practice, 24(2), pp. 234-250.

MICS (2019). "Early Childhood Development (ECD)". Snapshots of Key Findings Report Multiple Indicator Cluster Survey 2019, Thailand. Available https://mics-surveysprod.s3.amazonaws.com/MICS6/East\%20Asia\%20and\%20the\%20Pacific/T hailand/2019/Snapshots/Thailand\%202019\%20MICS\%20Statistical\%20Sna pshots_English.pdf.

The Business Research company (2019). "Global Child Care Market". Child Care Market - By Type (Baby And Child Day Care Centers, PreKindergarten And Preschool Centers, Nursery Schools, And Overall Child Care), Market Overview And Market Players, By Region, Opportunities And Strategies - Global Forecast To 2022. Available https://www.thebusinessresearchcompany.com/report/child-care-market.

Wieske, G. (2015). "The Importance of Child Care for Working Parents". Sandbox software. Available from https://www.runsandbox.com/blog/theimportance-of-child-care-for-working-parents. 
Wongboonsin K., Mason, K. O. and Choe, M.K. (1991). "Child care in Thailand: determinants and health consequences for preschool-aged children". Presented at the annual meeting of the American Sociologial Association, Cincinnati.

Wongboonsin, K. and Ruffolo, V.P. (1992). "Child care in Chiang Mai: determinants and health consequences for preschool-aged children". Presented at the Seminar on Child Care in Thailand: Determinants and Health Consequences for Preshcool Aged Children, Bangkok.

Woodill, G., Bernhard, J., and Prochner, L. (1992). International Handbook of Early Childhood Education. New York: Garland.

Unicef Thailand (2019). Early Childhood Development. Available from https://www.unicef.org/thailand/what-we-do/early-childhood-development. 